\title{
Assessment of a segregated medicated early weaning protocol for elimination of Actinobacillus pleuropneumoniae
}

\author{
Pablo Jesús Tamiozzo ${ }^{1 *}$ Alicia Isabel Carranza ${ }^{1}$ C \\ Bibiana Rosa Pelliza ${ }^{1} \odot$ Julián Parada $^{1,2} \odot$ Arnaldo Ambrogi $^{1}$
}

${ }^{1}$ Departamento de Patología Animal, Facultad de Agronomía y Veterinaria, Universidad Nacional de Río Cuarto (UNRC), Ruta 36 Km 601, Río Cuarto, 5800, Córdoba, República Argentina. E-mail: ptamiozzo@ayv.unrc.edu.ar. "Corresponding author.

${ }^{2}$ Consejo Nacional de Investigaciones Científicas y técnicas (CONICET), República Argentina.

ABSTRACT: To assess the success of a segregated medicated early weaning protocol for elimination of Actinobacillus pleuropneumoniae, ten consecutive batches of 100 pigs per batch weaned at 7-9 days of age were monitored at 21-22 weeks of age looking for presence of productive cough, presence of antibodies against the agent and pleuropneumonia-compatible lung lesions at slaughter. Also, whole tonsils were processed for A. pleuropneumoniae identification by both bacteriological isolation and nested-PCR using a direct method. Positive serological test $(1.4 \%)$ and PCR (3.5\%) results, suggested that A. pleuropneumoniae could not be eradicated in all batches, even using segregated medicated early weaning protocol.

Key words: swine, pleuropneumonia, Actinobacillus pleuropneumoniae, elimination, segregated medicated early weaning.

Avaliação de um protocolo de desmame precoce segregado medicado para a eliminação de Actinobacillus pleuropneumoniae

RESUMO: Para avaliar o sucesso de um protocolo de desmame precoce segregado medicado para a eliminação de Actinobacillus pleuropneumoniae, dez lotes consecutivos de 100 suínos por lote desmamados aos 7-9 dias de idade foram monitorados às 21-22 semanas de idade procurando a presença de tosse produtiva, presença de anticorpos contra o agente e lesões pulmonares compativeis com pleuropneumonia no abate. Além disso, as tonsilas inteiras foram processadas para a identificação de A. pleuropneumoniae por isolamento bacteriológico e nested PCR usando um método direto. Os resultados serológicos $(1,4 \%)$ e PCR $(3,5 \%)$ positivos sugerem que não foi possível erradicar em todos os lotes, mesmo usando um protocolo de desmame precoce segregado medicado.

Palavras-chave: suíno, pleuropneumonia, Actinobacillus pleuropneumoniae, eliminação, desmame precoce segregado medicado.

\section{INTRODUCTION}

Porcine pleuropneumonia caused by Actinobacillus pleuropneumoniae, is a contagious disease that may produce important economic losses in most pig-producing countries (GOTTSCHALK, 2012) as a result of deaths, treatments and control costs. For A. pleuropneumoniae eradication, application of some protocols has been reported, but no validated method is available. While depopulationrepopulation protocols are expensive (HARRIS, 2000; GOTTSCHALK, 2012), success of partial depopulation and antibiotic treatment protocols has been reported in only few cases (BÆKBO, 2001; ANDERSEN \& GRAM, 2004).

$A$. pleuropneumoniae colonizes the piglets at about 7-14 days (DRITZ et al., 1996).
Age of weaning and level of maternal antibodies may play an important role in the colonization of piglets by the pathogen (VIGRE et al., 2002). Even though the prevalence of colonized piglets around weaning time is low (CHIERS et al., 2002; VIGRE et al., 2002), there are differences in the pattern of colonized piglets clustering throughout and within the litters (TOBIAS et al., 2014a). These facts may have strong implications on the success of early weaning protocols to eradicate $A$. pleuropneumoniae, as piglets may carry the agent within the tonsils, being this the main contamination source of new facilities or naïve pig populations. Thus, medicated early weaning protocols seem an effective alternative for elimination of $A$. pleuropneumoniae from an $A$. pleuropneumoniae-positive sow herd (BAUM et al., 2010). Most of medicated early weaning protocols 
used in-fed medication of sows and parenteral medication in piglets (YESKE, 2009; ROTTO \& CLABORN , 2009; BAUM et al., 2010). However, the use of antibiotics seems not able to eliminate the pathogen from pigs' tonsils (ANGEN et al., 2008; FITTIPALDI et al., 2005).

Monitoring a pathogen free facility is a difficult task; even more for A. pleuropneumoniae for which "gold standard" is not well defined, considering that the agent is carried within tonsils of pigs without clinical signs. Thus, due to the lack of information in the literature concerning this type of eradication protocols for the pathogen, the objective of this study was to monitor the success of a segregated medicated early weaning program for $A$. pleuropneumoniae elimination by inspection of pleuropneumoniacompatible lung lesions, observation of cough, bacteriology, serology and PCR from tonsils.

\section{MATERIALS AND METHODS}

\section{The herd and historical data of the herd of origin}

The study was carried out in a new multi-site 4500-sow farm (herd B), with new facilities that would be populated with replacement gilts from the herd of origin (-herd A- a multi-site, 4500-sow commercial herd). In 2005, some sows from herd A rendered positive results to serotypes 3-6-8 using LC-LPS ELISA (Swinecheck ${ }^{\circledR}$ APP 3-6-8, Biovet, Canada) and A. pleuropneumoniae serotype 15 was isolated and identified from pigs with dyspnea and respiratory distress (ZIELINSKI et al., 2006). Then, in 2006, a partial depopulation program for eradication of $M$. hyopneumoniae was carried out in herd A (TAMIOZZO et al., 2011). Briefly, animals younger than 10 months were removed, and only the breeding animals remained (sows, gilts, and boars), which were vaccinated against $M$. hyopneumoniae (Respisure $\mathrm{ONE}^{\circledR}$, Pfizer, Argentina) and in-feed medicated with 100ppm of tiamulin (Dynamutilin ${ }^{\circledR}$ $10 \%$ premix, Novartis, Argentina) and 300ppm of chlortetracycline by using pulses of 15 days duration, then stopped for another 15 days for a 4-month-period, in order to decrease the bacterial load. Mating and breeding processes were interrupted for a 7-day-period and the empty facilities were cleaned (detergent DSC $1000^{\circledR}$, Bayer, Argentina) and disinfected (Virkon S, DuPont, Argentina). No replacement animals entered to the herd for a 4-month-period. While monitoring this eradication program, $82 \%$ (50 out of 61 ) of sows and $1.5 \%$ ( 2 out of 129 ) of 22 week-old pigs from the herd A were seropositive to species-specific ApxIV ELISA (IDEXX APP-ApxIV Ab test, US), a common toxin produced by all $A$. pleuropneumoniae serotypes.
Segregated medicated early weaning protocol

The study was conducted in summer, from December 2006 to February 2007. In this period, in herd $\mathrm{A}$, there were no clinical signs compatible with pleuropneumonia in either sows or pigs and vaccination against $A$. pleuropneumoniae was not practiced.

To perform the segregated medicated early weaning protocol, in herd A, ten consecutive batches of sows were treated with $100 \mathrm{ppm}$ of tiamulin -0.2 to $0.6 \mathrm{mg} / \mathrm{kg}$ - (Dynamutilin ${ }^{\circledR} 10 \%$ premix, Novartis, Argentina) and $400 \mathrm{ppm}$ of chlortetracycline -1 to $2.4 \mathrm{mg} / \mathrm{kg}$ - during the last 25 days of gestation and throughout the entire lactation period (Figure 1). Only the offspring of sows with a parity number of 3 or higher (one batch per week) was early segregated.

Then, ten consecutive batches of 360 piglets each (that corresponded to ten consecutive weeks of production) were weaned at 7-9 days of age, treated with tulathromycin - single IM injection, $2.5 \mathrm{mg} / \mathrm{kg}$ - $\left(\right.$ Draxxin $^{\circledR}$, Pfizer, Argentina) on the day of the weaning, and transferred weekly into clean (detergent DSC $1000^{\circledR}$, Bayer, Argentina) and disinfected (Virkon S, DuPont, Argentina) trucks to herd B, located 500 kilometers away from herd A. Piglets were transported separately, without any animals from other farms or other ages. One hundred and eighty piglets were transferred every Monday and the other 180 every Thursday. A rented truck was solely used for this protocol. Every time the truck came back to herd A it was cleaned, disinfected and remained there until next use.

At the moment of the study, in Herd B only one site III (growing pigs' site) had been built, while site I (breeding, gestation and farrowing site), was being built $3.5 \mathrm{~km}$ away approximately. Site III had two parallel barns and near each other. Each barn was divided into four rooms. Each room had 34 pens with space for 35 animals each. According to this, each room had a capacity for 1190 pigs and each barn had room for 4760 animals and each site III had capacity for 9520 animals (The farm would have four sites III).

For the study only one site-III was used. Each room was filled with two batches of piglets, in two weeks ( 720 pigs by room). Thus, one barn was filled in eight weeks ( 8 batches of piglets) and the remaining two batches were housed in one room of the adjacent barn of the same site III (Figure 1). Then these pigs were reared in site III, in the same pens where they arrived. When the pigs reached 21-22 weeks of age were sampled and observed looking for clinical signs (see below). Once these animals reached sexual maturity (at around 24 weeks of age) and after phenotypic selection the discarded animals were followed until slaughter. 


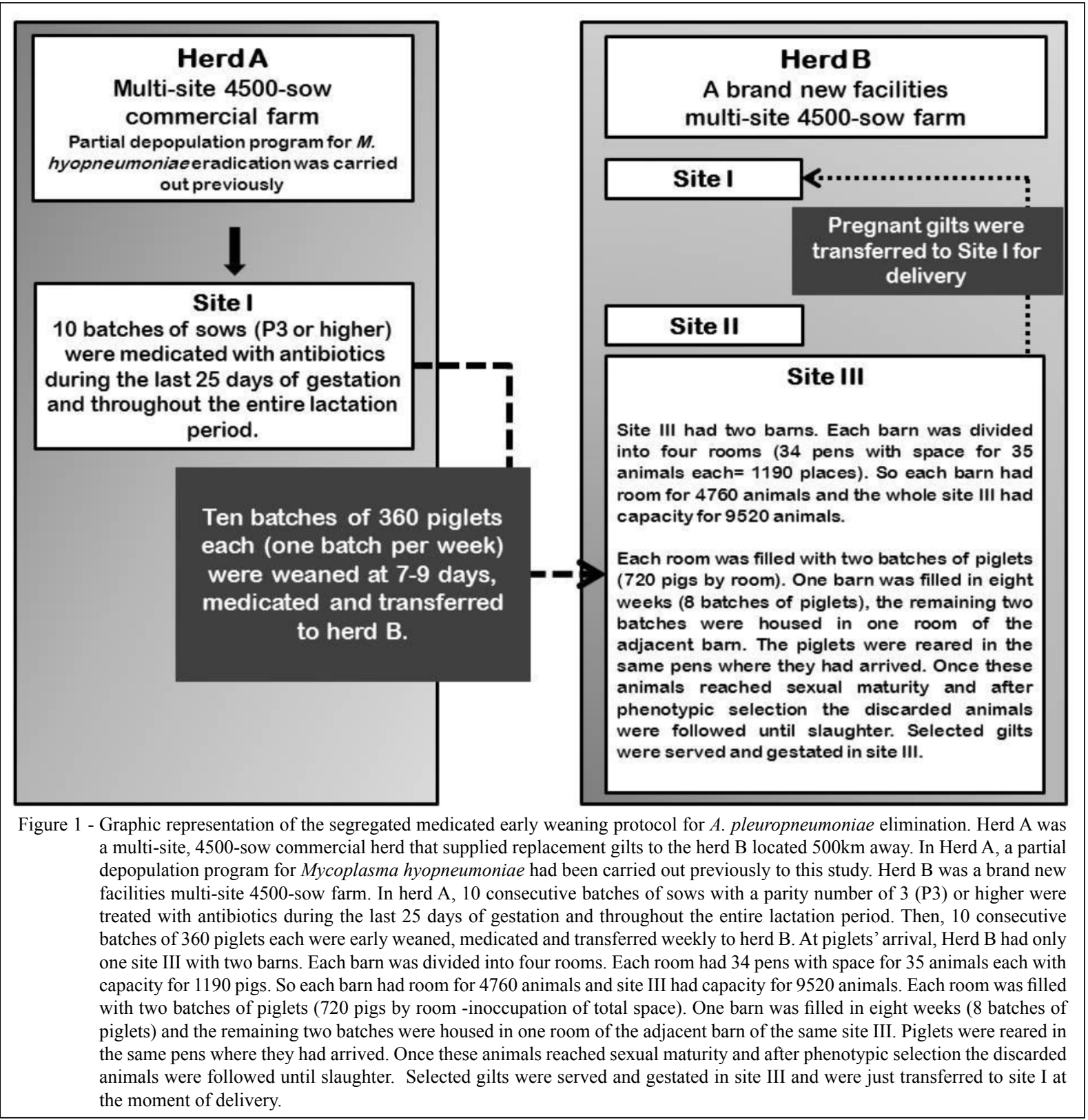

Selected gilts were served and gestated in site III and were just transferred to site I (that was already built) at the moment of delivery (Figure 1).

\section{Monitoring the eradication program}

To assess the success of the eradication protocol, productive cough was recorded in all ten groups (one group per week) that had arrived and grown in the new farm at 21-22 weeks of age. Pigs were forced to move by clapping. The number of coughing pigs was recorded during a 1 minute interval, repeating the procedure once. Then, the average proportion of coughing pigs was calculated.

One-hundred pigs from each group were bled and their serum tested by apxIV species-specific ELISA (IDEXX APP-ApxIV Ab test, US) at 21 weeks of age, looking for anti-apxIV antibodies. Serum samples were processed according to the manufacturer's instructions considering them as positive when the sample/positive ratio was equal to or greater than 50 . All suspected samples $(n=2)$, with sample/positive ratio values between 40 and 50, were considered as negative. 
At slaughter, between 18 and 50 pig lungs per batch were inspected looking for pleuropneumoniacompatible lung lesions considering that gross pathological lesions vary according to the clinical course of the disease. Briefly: 1) Peracute fibrinous/ necrotizing pneumonia (pleuropneumonia): extensive dissemination; associated with blood tinged fluid in the pleural cavity; extensive fibrinous pleuritis, 2) Acute/subacute fibrinous/necrotizing pneumonia (pleuropneumonia): predominantly caudodorsal; fibrinous pleuritis and 3) Chronic necrotizing pneumonia (pleuropneumonia): predominantly caudodorsal; firm capsulated processes with necrosis and abscesses; local fibrous pleuritis (SØRENSON et al., 2006).

Also, whole tonsils were collected for both isolation and detection of the agent by nested-PCR (nPCR) using a tonsil homogenate as described by FITTIPALDI et al. (2003). For bacteriological isolation, each whole tonsil was sprayed with alcohol and flamed for 5 seconds, a deep incision was done on the tonsil surface using sterile scalpels, then the incision was swabbed and the swabs were inoculated on blood agar (cross streaked with Staphylococcus epidermidis) and incubated at $37^{\circ} \mathrm{C}$ with $5 \% \mathrm{CO}_{2}$ for $18-24 \mathrm{hs}$. After that, a whole tonsil was placed in a sterile porcelain mortar, reduced to small pieces with sterile scissors; $2 \mathrm{~mL}$ of sterile Phosphate Buffered Saline were added and then vigorously macerated. DNA of the homogenate was extracted with DNAzol ${ }^{\circledR}$ (Invitrogen $^{\mathrm{TM}}$, Argentina). Amplification was performed under the conditions previously reported (SCHALLER et al., 2001).

\section{Statistical analysis}

A modified hypergeometric exact method was used in order to demonstrate population freedom from disease using imperfect tests (FreeCalc: Analyse). Results of disease free testing (EpiTools epidemiological calculators, <http://epitools.ausvet. com.au>, CAMERON \& BALDOCK, 1998) for ELISA and nPCR had the following parameters: For ELISA, the test sensitivity was set at 0.13 and the specificity at 1 , according to previous data (OPRIESSNIG et al., 2013), for PCR the sensitivity was set at 0.8 and the specificity at 1 considering results obtained by FITTIPALDI et al. (2003) when comparing a similar less sensitive PCR test (Adiavet App PCR) against other diagnostic techniques. For both, ELISA and PCR a hypothetical prevalence of $15 \%$ was assumed, considering the low transmission rate of the pathogen (TOBIAS et al., 2014b).

\section{RESULTS AND DISCUSSION}

The objective of this study was to monitor the success of a segregated medicated early weaning program for $A$. pleuropneumoniae elimination by using several diagnostic techniques. Conversely, in the case of $A$. pleuropneumoniae, differentiation of infection from disease is very important. The interpretation of the diagnostic technique depends on the desired eradication level, whether it be the absence of disease/infection, assuming the minimal prevalence of the causative agent, or the absolute absence of the pathogen.

To demonstrate the absence of the disease, two subjective diagnostic tools were used; cough monitoring and lung lesion observation at slaughter. No productive cough was detected in observed pigs. Even though productive cough is not the only clinical sign caused by an $A$. pleuropneumoniae infection, other signs such as fever and decrease in appetite can be observed (GOTTSCHALK, 2012). Other clinical signs other than cough were not investigated. Pleuropneumonia-compatible lesions were observed in $7.8 \%$ of lungs inspected (Table 1). However, other pathogens such as Actinobacillus suis, Salmonella cholerasuis or Pasteurella multocida can cause similar macroscopic lung lesions (GOTTSCHALK, 2012) but unfortunately their presence was not considered.

In order to demonstrate the presence of the infection we used an Apx IV ELISA test and nPCR from tonsils. Only 1.4\% (14/1000) of pigs was seropositive to Apx IV ELISA (Table 1). Batches 1 and 2 rendered negative results (Table 1). According to the FreeCalc assessment, these results are not adequate to assert that the population is free from disease (at the expected minimum prevalence of $15 \%$ ) so it may be concluded that the population is diseased at a confidence level of 1. This may be due to the fact that the ELISA used has high specificity and low sensitivity (OPRIESSNIG et al., 2013). Some false negative results would be obtained using the Apx IV ELISA test, since some strains of $A$. pleuropneumoniae are unable to produce apxIV toxin and infected pigs do not seroconvert (TEGETMEYER et al., 2008).

A. pleuropneumoniae was detected by nPCR in $3.5 \%$ of tonsils using the direct method previously reported (FITTIPALDI et al., 2003). Samples from batches 2, 3, 4 and 7 were negative; the remaining batches were positive (Table 1). The fact that there were positive batches may be explained by different patterns of clustering of colonized piglets throughout and within the litters (TOBIAS et al., 2014a), considering that some batches colonized and others did not. According to FITTIPALDI et al. (2003) the apxIV nPCR used in this study is more sensitive than other PCR tests (SIROIS et al., 1991; HERNANZ MORAL et al., 1999; SAVOYE et al., 
Table 1 - Number (percentages) of ApxIV ELISA, nPCR from tonsils and lung lesions detection out of total pigs tested from ten batches of 21-22 weeks old pigs.

\begin{tabular}{lccc}
\hline Batches & Apx IV ELISA & direct $n$ PCR from tonsils & Pleuropneumonia - compatible lung lesions \\
\hline 1 & $0 / 100(0)$ & $3 / 50(6)$ & $12 / 32(37.5)$ \\
2 & $0 / 100(0)$ & $0 / 29(0)$ & $1 / 26(3.8)$ \\
3 & $4 / 100(4)$ & $0 / 24(0)$ & N/D \\
4 & $1 / 100(1)$ & $0 / 30(0)$ & N/D \\
5 & $1 / 100(1)$ & $1 / 35(2.8)$ & $0 / 40(0)$ \\
6 & $2 / 100(2)$ & $1 / 18(5.5)$ & $3 / 45(6.6)$ \\
7 & $1 / 100(1)$ & $0 / 26(0)$ & $2 / 31(6.4)$ \\
9 & $1 / 100(1)$ & $3 / 41(7.3)$ & $0 / 15(0)$ \\
\hline 10 & $2 / 100(2)$ & $2 / 30(6.6)$ & $0 / 25(0)$ \\
\hline TOTAL & $2 / 100(2)$ & $1 / 32(3.1)$ & $19 / 242(7.8)$ \\
\hline
\end{tabular}

N/D: Not determined.

2000; CHIERS et al., 2001, LO et al., 1998; GRAM et al., 2000) being the best option when a high analytical sensitivity is needed, as in our case. However, in spite of the fact that this PCR is highly specific for $A$. pleuropneumoniae, some false-positive results can be obtained, mainly due to the cross-contamination on the routine to the diagnostic laboratories (FITTIPALDI et al., 2003); although, pertinent precautions were taken to avoid cross-contamination during the processing of the specimens (KWOK \& HIGUCHI, 1989). The FreeCalc assessment of PCR results was adequate to reject the null hypothesis but not to accept the alternate hypothesis. So, it may be concluded that the population is not free from disease, but that the prevalence is less than $15 \%$.

A. pleuropneumoniae was not isolated from the tonsils of sampled pigs. The "gold standard" for A. pleuropneumoniae infection is not clearly defined. However, in this context, isolation of the pathogen would have been the unambiguous proof of failure in the eradication program. Standard isolation of the agent from tonsils has low sensitivity because identification of A. pleuropneumoniae colonies is difficult due to the bacterial overgrowth.

It is at this point where interpretation of diagnostic techniques becomes crucial regarding the expected hypothetical prevalence in an eradication scenario, which depends on the desired eradication level, either assuming the minimal prevalence or the absolute absence of the causative agent. Due to the fact that both, ELISA and nPCR techniques have a specificity close to $100 \%$ (FITTIPALDI et al., 2003; OPRIESSNIG et al., 2013) the probability to find some false positive results decreases, especially for ELISA test, since its low sensitivity. Even assuming hypothetical prevalences of $50 \%$ or higher, it cannot be concluded that the population is free from the pathogen, but that the infection is present with lower values of prevalence (FreeCalc, data not shown). If prevalence of $50 \%$ or higher are considered, $A$. pleuropneumoniae eradication could not be achieved either assuming minimal prevalence or much less the pathogen absence.

Despite the absence of A.pleuropneumoniae growth and considering the lack of cough and the results from the FreeCalc assessment and the differences on serological and PCR results at batchlevel (Table 1), it can be concluded that some pigs were sub-clinically infected with A. pleuropneumoniae and the eradication program failed.

In spite of the early weaning of piglets and antibiotic treatment, A. pleuropneumoniae remained within the pigs' tonsils of some batches of segregated early weaned piglets (GOTTSCHALK, 2012) where horizontal transmission among pen mates occurred later (TOBIAS et al., 2014b). Horizontal transmission among other pigs within the farm is unlikely since there were no other animals in the herd. Close contact with wild boars is improbable as pigs are reared into wire fenced site III and airborne transmission of A. pleuropneumoniae over long distances is rare (TORREMORELL et al., 1997; JOBERT et al., 2000; NIELSEN, 2002; KRISTENSEN et al., 2004).

The possibility of the early weaned piglets becoming infected during transportation is unlikely, mainly because they were transported separately, 
without animals from other herds or other ages into a decontaminated whole truck. In this regard; although, the transmission of $A$. pleuropneumoniae by vehicles has been documented (FUSSING et al., 1998), effectiveness in reducing the number of bacteria by disinfectant used in the present study has been reported, when a truck tire sanitizer system was evaluated (AMASS et al., 2003). Besides, all the staff was strongly committed in order to achieve the eradication of the pathogen and the tasks were meticulously carried out.

The high percentage of seropositive sows from herd A using apx IV ELISA suggests an active circulation of $A$. pleuropneumoniae among the sow population. In this scenario, it could be inferred that; although, piglets received a high concentration of maternal antibodies by colostrum and milk, colonization cannot be avoided.

In the present study, only the offspring of sows with a parity number of 3 or higher were early weaned, medicated and transferred, considering that older sows have higher concentrations of all immunoglobulins (KLOBASA \& BUTLER, 1987). Referring specifically to A. pleuropneumoniae, FABLET et al. (2011) have reported higher antibody levels in older sows. However, in our study the presence of some seronegative sows (18\%) suggests the existence of subpopulation with lower levels of antibodies. Taking into account that a recent study did not show any association between sow parity and infection probability of piglets (TOBIAS et al., 2014a), hyperimmunization of any parity numbersows would be a good strategy to ensure a high level of colostral antibodies in piglets.

For A. pleuropneumoniae elimination from endemically infected farms, depopulation and restocking with pigs from pleuropneumonia-free herds can be used, but this method is expensive (GOTTSCHALK, 2012). Successful partial depopulation programs have already been reported (BÆKBO, 2001; ANDERSEN \& GRAM, 2004). However, there is a lack of information about the segregated medicated early weaning protocols. Usually, the revised protocols used in-fed medication of sows (tilmicosin) and parenteral medication in piglets, utilizing tulathromycin alone or combined with ceftiofur, lincomycin and florfenicol (YESKE, 2009; ROTTO \& CLABORN, 2009; BAUM et al., 2010).

Regarding treatment of sows, while the study was being carried out, an antibiotic sub-dose was detected, since higher doses of both, tiamulin and chlortetracycline could have been used. Concerning piglets treatment, at the moment of the study, tulathromycin was not widely used in our country thus a null resistance was assumed. It was chosen because it achieves high lung concentrations, has a long half-life and it has been pointed out as a therapy against gramnegative bacteria associated with swine respiratory disease complex (BENCHAOUI et al., 2004; NUTSCH et al., 2005). However, a further study demonstrated that tulathromycin did not eliminate A. pleuropneumoniae from pigs' tonsils (ANGEN et al., 2008).

Futurestudies toassess segregated medicated early weaning protocols for A. pleuropneumoniae elimination should be conducted in order to get alternatives to obtain $A$. pleuropneumoniae-free herds. An early weaning protocol such the used in this study, combined with accurate doses of suitable antibiotics, could get $A$. pleuropneumoniae-free offspring. In this regard, new antibiotics able to eliminate the agent from pigs' tonsils should be tested.

Despite the fact that some studies have reported success on $A$. pleuropneumoniae elimination using similar weaning and antibiotic treatment schemes, our results suggested that the agent was not eliminated. Some batches were test-negative at first because some of them were A. pleuropneumoniae-free or were subclinically infected, later proved to be test-positive, because some of them became infected or were $A$. pleuropneumoniae carriers.

\section{CONCLUSION}

In summary, under the conditions of this study, A. pleuropneumoniae cannot be eliminated using a segregated medicated early weaning protocol. More in-depth studies are necessary to evaluate the possibility of transmission of $A$. pleuropneumoniae in order to develop different strategies of control, based on early weaning schemes and monitored by different diagnostic techniques.

\section{BIOETHICS AND BIOSSECURITY COMMITTEE APPROVAL}

The study was performed according to the international guidelines of the Council for International Organizations of Medical Sciences $<$ CIOMS-https://cioms.ch/->.

\section{ACKNOWLEDGEMENTS}

This study was financially supported in part by PICTO 30511/2005 FONCyT-ANPCyT-MinCyT, República Argentina and PPI 2016-2018, 188/2016UNRC, República Argentina.

\section{DECLARATION OF CONFLICTING INTERESTS}

The authors declare no conflict of interest. The founding sponsors had no role in the design of the study; in the 
collection, analyses, or interpretation of data; in the writing of the manuscript, and in the decision to publish results.

\section{REFERENCES}

AMASS, S. et al. Pilot studies to evaluate the efficacy of a truck-mounted tire sanitizer system. Journal of Swine Health and Production, v. 11, n.6, p 277-283. 2003. Available from: <https://www.aasv.org/shap/ abstracts/abstract.php?v11n6p277>. Accessed: Dec. 11, 2017.

ANDERSEN, L. \& GRAM, S. A successful elimination of Actinobacillus pleuropneumoniae (serotype 2), Mycoplasma hyopneumoniae and PRRS (European and Vaccine-strain) by partial depopulation, early weaning and Tilmicosin (Pulmotil, Elanco) treatment. In: IPVS CONGRESS, 18, 2004. Hamburg, GERMANY. Proceeding... Hamburg: IPVS, 2008, p. 179.

ANGEN, Ø. et al. Effect of tulathromycin on the carrier status of Actinobacillus pleuropneumoniae serotype 2 in the tonsils of pigs. The Veterinary Record, v. 163, n. 15, p. 445-447. 2008. Available from: <https://www.ncbi.nlm.nih.gov/pubmed/18849576>. Accessed: Aug. 11, 2017. doi: 10.1136/vr.163.15.445.

BÆKBО, P. Eradication of Mycoplasma hyopneumoniae and Actinobacillus pleuropneumoniae. In: COLLEGE OF VETERINARY MEDICINE. International symposium on swine disease eradication. St Paul, Minnesota: University of Minnesota, 2001. v.1, p.27-33.

BAUM, D. H. et al. Medicated early weaning for elimination of Mycoplasma hyopneumoniae and Actinobacillus pleuropneumoniae from an $M$ hyopneumoniae- and A pleuropneumoniae-positive sow herd. In: AASV MEETING, 41, 2010. Omaha, Nebraska, USA. Proceeding... Omaha, Nebraska: AASV, 2010, p. 299-300.

BENCHAOUI, $\mathrm{H}$. et al. Pharmacokinetics and lung tissue concentrations of tulathromycin in swine. Journal of Veterinary Pharmacology and Therapeutics, v. 27, n.4, p. 203-210. 2004. Available from: $<$ https://www.ncbi.nlm.nih.gov/pubmed/15305848>. Accessed: Dec. 11, 2017. doi: 10.1111/j.1365-2885.2004.00586.x.

CAMERON, A. \& BALDOCK, F. A new probability formula for surveys to substantiate freedom from disease. Preventive Veterinary Medicine, v. 34, p. 1-17. 1998. Available from: <https:// www.ncbi.nlm.nih.gov/pubmed/9541947>. Accessed: Aug. 15, 2017. doi: 10.1016/S0167-5877(97)00081-0.

CHIERS, K. et al. Detection of Actinobacillus pleuropneumoniae in cultures from nasal and tonsillar swabs of pigs by a PCR assay based on the nucleotide sequence of a dsbE-like gene. Veterinary Microbiology, v.83, n. 2, p. 147-159. 2001. Available from: $<$ https://www.ncbi.nlm.nih.gov/pubmed/11557155>. Accessed: Sept. 1, 2017. doi: 10.1016/S0378-1135(01)00414-X.

CHIERS, K. et al. Actinobacillus pleuropneumoniae infections in closed swine herds: infection patterns and serological profiles. Veterinary Microbiology, v. 85, n. 4, p. 343-352. 2002. Available from: $<$ https://www.ncbi.nlm.nih.gov/pubmed/11856584>. Accessed: Dec. 11, 2011. doi: 10.1016/S0378-1135(01)00518-1.

DRITZ, S. et al. Growth and microbial flora of non medicated, segregated, early weaned pigs from a commercial swine operation. Journal of American Veterinary Medicine Association, v.208, n.5, p. 711-715. 1996. Available from: <https://www.ncbi.nlm.nih. gov/pubmed/8617629>. Accessed: Sept. 21, 2017.
FABLET, C. et al. Longitudinal study of respiratory infection patterns of breeding sows in five farrow-to-finish herds. Veterinary Microbiology, v. 147, n 3-4, p. 329-339. 2011. Available from: $<$ https://www.ncbi.nlm.nih.gov/pubmed/20696539>. Accessed: Dec. 11, 2017. doi: 10.1016/j.vetmic.2010.07.005.

FITTIPALDI, N. et al. Assessment of the efficacy of tilmicosin phosphate to eliminate Actinobacillus pleuropneumoniae from carrier pigs. Canadian Journal of Veterinary Research, v. 69, n. 2, p. 146-150. 2005. Available from: <https://www.ncbi.nlm.nih. gov/pubmed/15971680>. Accessed: Aug. 11, 2017.

FITTIPALDI, N. et al. Evaluation and field validation of PCR tests for detection of Actinobacillus pleuropneumoniae in subclinically infected pigs. Journal of Clinical Microbiology, v.41, n. 11 p. 5085-5093, 2003. Available from: <https://www.ncbi.nlm.nih. gov/pubmed/14605143>. Accessed: Dec. 05, 2007. doi: 10.1128/ JCM.41.11.5085-5093.2003.

FUSSING, V. et al. Evaluation and application of ribotyping for epidemiological studies of Actinobacillus pleuropneumoniae in Denmark. Veterinary Microbiology, v 62, n. 262, p. 145-162. 1998. Available from: <https://www.ncbi.nlm.nih.gov/pubmed/9695287>. Accessed: Dec. 05, 2017. doi: 10.1016/S0378-1135(98)00205-3.

GOTTSCHALK, M. Actinobacillosis. In: ZIMMERMAN, J.J. et al (Eds). Diseases of swine. 10 ed. Chichester: Wiley-Blackwell, 2012. p. 653-669.

GRAM, T. et al. An Actinobacillus pleuropneumoniae PCR typing system based on the apx and omlA genes-evaluation of isolates from lungs and tonsils of pigs. Veterinary Microbiology, v. 75, n. 1, p. 43-57. 2000. Available from: <https://www.ncbi.nlm.nih.gov/ pubmed/10865151>. Accessed: Sept. 1, 2017. doi: 10.1016/S03781135(00)00206-6.

HARRIS, D.L. Multi-site pig production. Ames: Iowa State University, 2000. 217p.

HERNANZ MORAL, C. et al. Molecular cloning and sequencing of the aroA gene from Actinobacillus pleuropneumoniae and its use in a PCR assay for rapid identification. Journal of Clinical Microbiology, v. 37, n. 5, p. 1575-1578. 1999. Available from: <https://www.ncbi. nlm.nih.gov/pubmed/10203526>. Accessed: Sept. 1, 2017.

JOBERT, J. et al. Experimental aerosol transmission of Actinobacillus pleuropneumoniae to pigs. Canadian Journal of Veterinary Research, v. 64, n. 1, p. 21-26. 2000. Available from: $<$ https://www. ncbi.nlm.nih.gov/pubmed/10680652>. Accessed: Jan. 1, 2018.

KLOBASA, F. \& BUTLER, J. Absolute and relative concentrations of immunoglobulins $\mathrm{G}, \mathrm{M}$, and $\mathrm{A}$, and albumin in the lacteal secretion of sows of different lactation numbers. American Journal of Veterinary Research, v. 48, n. 2, p. 176-182. 1987.

KRISTENSEN, C.S. et al. Demonstration of airborne transmission of Actinobacillus pleuropneumoniae serotype 2 between simulated pig units located at close range. Veterinary Microbiology, v. 98, n. 3-4, p. 243-249. 2004. Available from: <https://www.ncbi.nlm.nih. gov/pubmed/15036533>. Accessed: Sept. 1, 2017. doi: 10.1016/j. vetmic.2003.10.026.

KWOK, S. \& HIGUCHI, R. Avoiding false positives with PCR. Nature. v. 339, p. 237-238.1989. Available from: <https:/www. ncbi.nlm.nih.gov/pubmed/2716852>. Accessed: May. 4, 2004. doi: $10.1038 / 339237 \mathrm{a} 0$. 
LO, T.M. et al. Detection and identification of Actinobacillus pleuropneumoniae serotype 5 by multiplex PCR. Journal of Clinical Microbiology, v.36, n. 6, p. 1704-10. 1998. Available from: <https:// www.ncbi.nlm.nih.gov/pubmed/9620404>. Accessed: Sept. 1, 2017.

NIELSEN, J.P. Transmission of pathogens: Danish SPF pig herds and airborne Actinobacillus pleuropneumoniae. In: COLLEGE OF VETERINARY MEDICINE. International symposium on swine disease eradication. St Paul, Minnesota: University of Minnesota, 2002. v.1, p.27-33.

NUTSCH, R. et al. Efficacy of tulathromycin injectable solution for the treatment of naturally occurring Swine respiratory disease. Veterinary Therapeutics, v. 6, n. 2, p. 214-224. 2005. Available from: <https:// www.ncbi.nlm.nih.gov/pubmed/16094568>. Accessed: Jan. 10, 2017.

OPRIESSNIG, T. et al. Evaluation of diagnostic assays for the serological detection of Actinobacillus pleuropneumoniae on samples of known or unknown exposure. Journal of Veterinary Diagnostic Investigation, v. 25, n. 1, p. 61-71. 2013. Available from: $<$ https://www.ncbi.nlm.nih.gov/pubmed/23293160>. Accessed: Jul. 11, 2017. doi: 10.1177/1040638712469607.

ROTTO, H. \& CLABORN, J. Actinobacillus pleuropneumoniae (APP) case study- elimination and diagnostic test decisions. In: AASV ANNUAL MEETING, 2009. Dallas, Texas, USA. Proceeding... Dallas, Texas: AASV, 2009, p. 435- 438.

SAVOYE, C. et al. A PCR assay used to study aerosol transmission of Actinobacillus pleuropneumoniae from samples of live pigs under experimental conditions. Veterinary Microbiology, v. 73, n. 4, p. 337-347 2000. Available from: $<$ https://www.ncbi.nlm.nih.gov/pubmed/10781732>. Accessed: Sept. 1, 2017. doi: 10.1016/S0378-1135(00)00181-4.

SCHALLER, A. et al. Identification and detection of Actinobacillus pleuropneumoniae by PCR based on the gene apxIVA. Veterinary Microbiology, v.79, n.1, p. 47-62. 2001. Available from: <https:// www.ncbi.nlm.nih.gov/pubmed/11230928>. Accessed: Jan. 15, 2008. doi: 10.1016/S0378-1135(00)00345-X.

SIROIS, M. et al. Construction of a DNA probe and detection of Actinobacillus pleuropneumoniae by using polymerase chain reaction. Journal of Clinical Microbiology, v. 29, n. 6, p. 1183-7. 1991. Available from: <https:/www.ncbi.nlm.nih.gov/ pubmed/1864937>. Accessed: Sept. 1, 2017.

SØRENSON, V. et al. 2006. Diseases of the Respiratory System. In: STRAW, B. et al (Eds). Diseases of swine. 9 ed. Oxford: Blackwell, 2006. p. 149-178.
TAMIOZZO, P. et al. Monitoring the presence of Mycoplasma hyopneumoniae in swine farms during the implementation of eradication programs. Ciência Rural, v.41, n.4, p 699-705. 2011. Available from: $<$ http://www.scielo.br/scielo.php?script=sci_arttext\&pid=S0103$84782011000400025 \& \operatorname{lng}=$ en\&nrm=iso $>$. Accessed: Apr. 15, 2015. doi: $10.1590 / \mathrm{S} 0103-84782011005000038$.

TEGETMEYER, H. et al. ISApl1, a novel insertion element of Actinobacillus pleuropneumoniae, prevents ApxIV-based serological detection of serotype 7 strain AP76. Veterinary Microbiology, v. 128, n. 4-3, p. 342-353. 2008. Available from: <https://www.ncbi. nlm.nih.gov/pubmed/18065168>. Accessed: Jan. 15, 2017. doi: 10.1016/j.vetmic.2007.10.025.

TOBIAS, T.J. et al. Transmission of Actinobacillus pleuropneumoniae among weaned piglets on endemically infected farms. Preventive Veterinary Medicine, v . 117, n. 1, p. 207214. 2014a. Available from: <https://www.ncbi.nlm.nih.gov/ pubmed/25156946>. Accessed: Jul. 11, 2017. doi: 10.1016/j. prevetmed.2014.07.017.

TOBIAS, T.J. et al.A cohort study on Actinobacillus pleuropneumoniae colonisation in suckling piglets. Preventive Veterinary Medicine, v. 114 , n. 3-4, p. 223-230. 2014b. Available from: <https://www. ncbi.nlm.nih.gov/pubmed/24630401>. Accessed: Jul. 11, 2017. doi: 10.1016/j.prevetmed.2014.02.008.

TORREMORELL, M. et al. Airborne transmission of Actinobacillus pleuropneumoniae and porcine reproductive and respiratory syndrome virus in nursery pigs. American Journal of Veterinary Research, v. 58, n. 8, p. 828-32. 1997. Available from: <https:// www.ncbi.nlm.nih.gov/pubmed/9256964>. Accessed: Sept. 1, 2017.

VIGRE, H. et al. Transmission of Actinobacillus pleuropneumoniae in pigs under field-like conditions: emphasis on tonsillar colonisation and passively acquired colostral antibodies. Veterinary Microbiology, v.89, n.2-3, p. 151-159. 2002. Available from: $<$ https://www.ncbi.nlm.nih.gov/pubmed/12243892>. Accessed: Sept. 20, 2007. doi: 10.1016/S0378-1135(02)00149-9.

YESKE, P. Using diagnostics to assess control strategies and monitor health status: Field experiences- Actinobacillus pleuropneumoniae. In: AASV ANNUAL MEETING PRE-CONFERENCE SEMINARS, 2009. Dallas, Texas, USA. Proceeding... Dallas, Texas: AASV PRECONFERENCE SEMINARS, 2009, p. 19-20.

ZIELINSKI, G. et al. Detección de Actinobacillus pleuropneumoniae serovar 15 en Argentina. Revista de Medicina Veterinaria, v.87, p. 147-150. 2006. 